\title{
Riesgos y retos en la intervención social en un contexto de austeridad: una perspectiva desde las entidades del tercer sector en Navarra ${ }^{1}$
}

\section{Lucía Martínez Virto}

Departamento de Trabajo Social, Universidad Pública de Navarra Grupo ALTER y Cátedra de Investigación para la Igualdad y la Integración Social (CIPARAIIS)

<lucia.martinez@unavarra.es>

Etxeetako beharren gorakadak eta gizarte-arretarako zerbitzuen eta eragileen baliabideei dagokienez izandako murrizketek zalantza, ziurgabetasun eta zailtasunez beteriko agertokia marrazten dute, eta horrek, aldi berean, gizarte-erakundeen esku hartzeko gaitasuna murriztea eragiten du. Zailtasunak dituzten etxeetan bizi diren 52 lagunen bizi-kontakizunen eta Nafarroan kokatzen diren Hirugarren Sektoreko beste 30 eragileren ikerketaren bitartez, xehetasunez hurreratuko gara sektore horrek, gaur egun, gainditu behar dituen arrisku eta erronka nagusietara. Emaitzak ikusirik, egitura horien ahultzeak pobrezia-zorroak egonkortzea eragin dezakeela jakinarazten da.

\section{GAKO-HITZAK:}

Krisia, Hirugarren Sektorea, murrizketak, gizartean esku hartzea, ziurgabetasuna, gainkarga.
El aumento de las necesidades de los hogares y la reducción de recursos en los servicios y entidades de atención social dibujan un escenario cargado de dilemas, incertidumbres y dificultades, que contribuyen a reducir la capacidad de intervención de las entidades sociales. A través del estudio de 52 relatos de vida de personas de hogares en situación de dificultad y de casi una treintena de experiencias referidas por entidades del tercer sector en Navarra, se abordarán de manera pormenorizada los principales riesgos y retos a los que se enfrenta actualmente el tercer sector. A partir de los resultados, se alerta de que el debilitamiento de estas estructuras supone el riesgo de afianzar las bolsas de pobreza.

\section{Palabras clave:}

Crisis, tercer sector, recortes, intervención social, incertidumbre, sobrecarga. 


\section{Introducción}

Las necesidades de los hogares se han visto incrementadas en número e intensidad por la confluencia de diversos factores: por un lado, la prolongación de la crisis, la alta tasa de desempleo, la falta de empleo -especialmente para algunos colectivosy el agotamiento de las prestaciones; y por otro, los recortes implementados en protección y atención social. Todo ello perfila un escenario que incrementa y complica el día a día de las familias, al tiempo que reduce su capacidad de encontrar apoyos, lo que aumenta el riego de que se desarrollen procesos de exclusión social más rápidos e intensos.

A lo largo de este texto, se pretende reflexionar sobre la realidad cotidiana de los servicios y entidades de atención social a partir de 52 relatos de vida de usuarios/as y de las experiencias referidas por más de una treintena de entidades del tercer sector de Navarra². Con ello, se tratarán de identificar los efectos que está suponiendo el debilitamiento de estas estructuras en la intervención social. Para ello, se atenderá, en primer lugar, al papel que juegan los soportes sociales en la prevención y amortiguación de muchos procesos de exclusión social. En segundo lugar, a partir de las experiencias de personas usuarias y profesionales se identificaran las principales dificultades a las que se enfrentan las entidades ante el riesgo grave de perder la capacidad y calidad de intervenir. Finalmente, a partir de este contexto se expondrán algunas reflexiones sobre los retos que se deben afrontar en un escenario de austeridad como el actual.

\section{La extensión de la crisis y las políticas de austeridad debilitan la protección social}

Numerosos trabajos han constatado en los últimos años el impacto de la crisis en términos de pobreza, desigualdad y exclusión social. Según los últimos datos de la Encuesta de Condiciones de Vida (Instituto Nacional de Estadística, 2014), la tasa de riesgo de pobreza con alquiler imputado ${ }^{3}$ ha aumentado, entre 2009 y 2013 , en 1,4 puntos porcentuales (del $17,3 \%$ al 18,7\% del total de hogares en España). Así mismo, en términos de aumento de la desigualdad, cabe subrayar el incremento del coeficiente de $\mathrm{Gini}^{4}$ del 30,5 al 31,1.

${ }^{2}$ El trabajo de campo se desarrolló en el marco de la Cátedra de Investigación para la Igualdad y la Integración Social (CIPARAIIS, Universidad Pública de Navarra) y dio pie al II Informe CIPARAIIS sobre Desigualdad Social en Navarra (Laparra, 2015).

3 El alquiler imputado se aplica a los hogares que no pagan un alquiler completo, por ser propietarios, o por ocupar una vivienda alquilada a un precio inferior al de mercado o a título gratuito. El valor que se imputa es el resultado de restar el alquiler realmente abonado (si lo hubiera) al que se pagaría en el mercado por una vivienda similar a la ocupada.

${ }^{4}$ La tasa de riesgo de pobreza, según la Encuesta de Condiciones de Vida, corresponde al porcentaje de personas con ingresos por debajo del $60 \%$ de la mediana de los ingresos anuales por unidad de consumo. El coeficiente de Gini es una medida de desigualdad que toma el valor o en caso de equidad perfecta y el valor 100 en caso de desigualdad perfecta.
A pesar de la relevancia de estas cifras, las consecuencias de la crisis son especialmente alarmantes si se atiende al incremento de la exclusión más severa. Según los últimos datos publicados en esta materia en el VII Informe sobre exclusión y desarrollo social en España (Lorenzo, 2014), la exclusión severa alcanza a 5 millones de personas en España, una cifra que, en términos de hogares, asciende a más de un millón y medio (1.552.000). Es decir, se constata un incremento del $69,8 \%$ con respecto a los niveles de exclusión severa de 2007.

El aumento de la exclusión social y la desigualdad se explica, en buena parte, por la destrucción de empleo, la prolongación de las situaciones de desempleo y los déficits del sistema de protección social en España. Sin embargo, las decisiones políticas que se toman en este contexto, en el sentido de impulsar un modelo inclusivo o, por el contrario, limitar las estructuras de protección social, podrían estar contribuyendo a definir este escenario.

Recientes análisis han comenzado a constatar la pérdida de capacidad de apoyo de los diferentes mecanismos de protección social, familiar y técnica, fundamentales hasta ahora para muchos hogares. Tanto Lorenzo (2014), a escala estatal, como Frazer y Marlier (2014), a escala internacional, coinciden en dos conclusiones fundamentales al abordar el impacto social de la crisis y las estrategias de austeridad implementadas en los últimos años. Por un lado, que la reducción de los apoyos públicos, la sobrecarga de las redes sociales y familiares próximas, la falta de ingresos y el agotamiento de prestaciones en contextos de desempleo prolongado contribuyen al desarrollo de itinerarios de exclusión muy rápidos y severos. Por otro, que los recortes en protección social de carácter técnico y económico ensanchan las brechas de desigualdad social. Por tanto, ambos análisis alertan de que el aumento de la desigualdad social en España se debe, en buena medida, tanto al debilitamiento de las estructuras de apoyo de los hogares como a las políticas de austeridad implementadas en los últimos años.

\section{Las prestaciones económicas, la atención técnica y la familia como principales soportes de los hogares}

La Real Academia Española define ‘soporte’ como un "apoyo o sostén” ante situaciones de dificultad. En los espacios de exclusión e integración, los soportes serían, por tanto, aquellos apoyos con los que cuentan los hogares ante situaciones de necesidad. El objetivo de estos soportes es apoyar al hogar hasta que la situación de necesidad mejore, por lo que pueden prevenir o retrasar la caída en situaciones de mayor dificultad. Éste es el sentido que, a partir de los relatos analizados, encontramos en los soportes: una malla de seguridad que evita caídas rápidas, pero que, con la extensión de la crisis y los recortes, podría empezar a debilitarse. 
El análisis realizado constata la importancia cardinal que las prestaciones sociales, los programas de atención social, las entidades y las redes sociales ejercen como soportes fundamentales que rescatan, apoyan o compensan las situaciones de dificultad económica, social y simbólica de los hogares. Por tanto, podrían definirse como unos agentes fundamentales en la constitución de la última red de protección social de estas familias.

\subsection{Las prestaciones sociales previenen situaciones de necesidad}

La pérdida de ingresos es un desencadenante fundamental de los itinerarios de exclusión. Las diferentes prestaciones, en sus más diversos niveles de protección, constituyen el elemento ineludible de resistencia, y de ahí, su importancia cardinal en la prevención de estas trayectorias. Sin embargo, su duración tiene caducidad, y su cuantía se va progresivamente reduciendo conforme las situaciones de desempleo o ausencia de ingresos se prolongan, tal y como ilustra el relato de José:

El paro ha ido agotándose: de los 11 años, me dieron 18 meses, porque como tuvimos un expediente de regulación de la empresa e ibas cogiendo del paro [...]. Después, entre una cosa y otra generé otros 10 meses, y esos 10 meses se me han acabado, se me acabaron en diciembre del año pasado, y desde enero hasta ahora, pues los 400 euros que te dan (José, 42 años, Navarra).

Las situaciones de desempleo, en un contexto con escasas oportunidades de reincorporación laboral como el actual, se enfrentan mejor con el derecho reconocido a una prestación contributiva. La mayor cuantía de sus prestaciones (con respecto al resto de ayudas y subsidios) y los meses de percepción adquiridos suponen la garantía de un mayor tiempo de protección. Además, el acceso a las prestaciones contributivas es percibido como un derecho adquirido, por lo que su percepción está exenta, en la mayoría de los casos, del carácter vergonzante implícito en otras prestaciones asistenciales.

En el siguiente nivel de protección, no contributivo por desempleo, se encuentran los diferentes subsidios y rentas de activación, que, en función de las características de los núcleos, tienen o no una mayor duración. Su cuantía, con respecto al nivel contributivo, se reduce considerablemente (entre 400 y 450 euros, dependiendo de la prestación y la persona beneficiaria), por lo que habitualmente se combinan con apoyos familiares o de entidades sociales (banco de alimentos o ayudas de emergencia a vivienda, entre otras).

Finalmente, las rentas mínimas autonómicas constituirían el último nivel de protección, pero aunque su cuantía es mayor, están sujetas a requisitos de acceso y su duración es determinada, según las diferentes regulaciones autonómicas. Por ello, los niveles de protección asistenciales, si bien tienen como objetivo prevenir la ausencia total de ingresos, muestran numerosas carencias en su protección.

A partir de los relatos de vida analizados, se ha podido comprobar que el descenso de las cuantías, el agotamiento progresivo de las sucesivas ayudas y la pérdida de tiempo de protección son los factores que motivan el inicio, real y simbólico, de las trayectorias de exclusión en muchas familias. En los meses que duran las prestaciones, los hogares manifiestan encontrar un apoyo que previene los itinerarios de exclusión, pero su finalización supone una fuerte y rápida caída en situaciones de mayor necesidad.

\subsection{Tener redes sociales permite un mayor aguante}

Los primeros estudios sobre el impacto de la crisis indicaban que el 'colchón familiar' tenía un destacado papel, al ejercer como amortiguador de la cohesión social (Cantó, 2010; Laparra y Pérez, 2011; Martínez Virto, 2013). Dicha realidad también se ha constatado en los relatos analizados, lo cual muestra la importancia del apoyo informal como una ayuda imprescindible para compensar las dificultades, prevenir privaciones o, en los casos más extremos, subsistir en la exclusión. El destacado papel que juega como malla de resistencia se manifiesta de manera recurrente en hogares. A modo de ejemplo, se destaca el apoyo de los/as pensionistas, la presencia de 'remesas invertidas' en aquellos hogares de origen extranjero que ahora necesitan ayuda en la sociedad de acogida u otros apoyos, como los materializados en acogimientos tras la pérdida de la vivienda debida a un desahucio.

Si bien todos estos apoyos tienen un cierto componente material (dinero, comida, vivienda o empleo), cada vez son más los casos que, como Esmeralda, ya no pueden ser apoyados por sus familias. Ello es debido con frecuencia a que la crisis también ha alcanzado a los núcleos que tradicionalmente prestaban ayuda, por lo que no pueden ofrecer apoyo económico ni material, a pesar de que quieran hacerlo.

No tengo apoyo familiar, mi familia está como yo también, o sea, somos cinco hermanos, yo soy la mayor, y también andan igual (Esmeralda, 24 años, Navarra).

Por ello, se constata que la familia y las amistades son fundamentales para compensar las situaciones de necesidad de hogares cercanos. Sin embargo, su apoyo no es universal, debido a que las personas y hogares que no tienen familia, o aquellas que la tienen, pero no pueden ser ayudadas, están viviendo una situación de especial vulnerabilidad. 
3.3. Los servicios de intervención social rescatan a las personas sin apoyos y trabajan por su inclusión social

Por último, uno de los soportes más potentes identificados en los relatos han sido, precisamente, los servicios y programas de atención social. Los hogares con situaciones de desempleo prolongado y falta de oportunidades laborales, sin ingresos y sin fuertes apoyos han acudido a los diferentes servicios sociales, tanto a los de carácter público como a las entidades del tercer sector. Las principales demandas que se han identificado, tanto en los relatos de los hogares como en las memorias de las entidades del tercer sector analizadas, han sido las de orientación y acogida, el acompañamiento en intermediación laboral o la solicitud de ayudas (económicas o en especie) de emergencia (Cáritas, 2013). Todas ellas evidencian las intensas necesidades laborales y de supervivencia que padecen los hogares.

\subsubsection{Los servicios de incorporación laboral para colectivos en situación o riesgo de exclusión social}

El empleo es el mecanismo de integración por excelencia, y así lo corroboran las diversas trayectorias positivas que se han identificado. Entre ellas, destaca la de Said, un claro ejemplo de que, ante un itinerario de descenso motivado por la pérdida del empleo en 2009, la intermediación laboral a través de una entidad del tercer sector especializada en la incorporación social y el consecutivo acceso al empleo supone el ascenso de un hogar hacia situaciones de mayor integración y estabilidad. Esta mejoría se materializa en la alegría y tranquilidad que Said trasmite en su discurso, pero desde una perspectiva técnica se constata en la prevención de la pérdida casi total del capital humano de su hogar, que, si el desempleo se hubiera alargado, podría haber culminado en importantes privaciones de carácter básico y en el enquistamiento de ese hogar en la exclusión social más severa.

Igualmente, a través de Miguel, joven navarro de 23 años, y de Dunia (37 años, Argelia), se puede comprobar cómo el acceso a un empleo ha supuesto un cambio radical en sus discursos. Miguel, tras enfrentar un joven matrimonio y el nacimiento de una niña sin apoyos, encuentra un empleo precario e inestable como repartidor. Cuando queda en desempleo (sin derecho a seguros sociales), pierde su vivienda y su familia se ve obligada a vivir en un coche. Finalmente, gracias a un programa de inserción de una entidad del tercer sector, encuentra un empleo que, aunque tiene un salario limitado, le reporta una estabilidad laboral de tres años. Por otro lado, Dunia, a pesar de su elevada formación (ingeniera), encontraba serias dificultades para entrar en el mercado de trabajo. Afortunadamente, el empleo de inserción al que ha accedido a través del apoyo e intermediación de una entidad social le ha reportado, además de la estabilidad y mejora económica del hogar, el acceso a los derechos sociales mediante la cotización, una mejora de su autoestima y tejer redes de amistad fuertes entre compañeros de trabajo.

Con estos tres ejemplos, se evidencia el papel fundamental que están jugando en la crisis las entidades sociales. El asesoramiento y acompañamiento técnico son la herramienta más efectiva para prevenir las situaciones de exclusión más agudas y para promover itinerarios de reincorporación laboral. Ésta es precisamente una de las recomendaciones que nos llegan desde Europa, la de impulsar políticas de activación adaptadas a los colectivos con más dificultades de acceso al mercado de trabajo (Frazer y Marlier, 2014). A partir del acceso al empleo, las dificultades de las familias se reducen, las condiciones de vida de sus miembros mejoran, la armonía familiar contribuye a crear climas de convivencia más saludables y se previene el enquistamiento de muchos hogares en situaciones de dificultad que, si se prolongaran, podrían tener un carácter irreversible.

\subsubsection{Las entidades y ayudas de emergencia social compensan las privaciones más básicas}

Debido al incremento de hogares con necesidades severas, tanto en entidades como en servicios sociales públicos se ha observado un aumento de la demanda de las ayudas de emergencia y de apoyos para las necesidades más básicas, entre las que destacan la vivienda, los suministros y la alimentación. El alto coste de la vivienda, su carácter de bien básico y la necesidad de garantizar el pago de los suministros como requisito ineludible para mantener el bienestar del hogar hacen del pago puntual de estos gastos fijos una de las necesidades más manifestadas en los relatos. La pérdida de la vivienda es el factor que motiva una caída más rápida y extrema en la exclusión social, y así lo demuestran numerosos testimonios, como el de Manuel o Grace.

No es sólo decir la hipoteca, es que luego viene la luz, viene el gas, viene el seguro del gas, el seguro del otro (Manuel, 46 años, Navarra).

Mi marido sí está trabajando, pero yo estoy sin trabajo y tengo dos niñas, y tenemos una hipoteca de piso, que ahora es muy difícil, la verdad, con los niños, y encima con la hipoteca..., estamos que no damos abasto (Grace, 30 años, Malî).

Tras un desahucio, la situación de una familia puede caer desde posiciones de relativa estabilidad a situaciones de necesidad extrema. Por el contrario, acceder a una residencia adecuada, prevenir su pérdida o garantizar su mantenimiento, e impulsa y mantiene las situaciones de integración. Prevenir las situaciones de exclusión residencial a través de la gestión de ayudas de emergencia para la vivienda, de avales o apoyos puntuales para el pago de suministros son algunas de las actuaciones identificadas que han permitido contrarrestar el riesgo existente de perder la vivienda. Aun así, en algunos casos, los desahucios se han hecho efectivos, y tras ellos, la 
gestión de las entidades sociales ha permitido que algunas familias hayan podido acceder a viviendas de integración social.

Por otro lado, el apoyo de las entidades del tercer sector también ha estado definido por la gestión de ayudas y combinación de programas destinados a garantizar las necesidades más básicas de los hogares. Entre estas actuaciones, destaca la gestión de ayudas como los complementos de la renta de inclusión social (la renta mínima de Navarra), la gestión del banco de alimentos para hogares tras el agotamiento de las rentas mínimas o la combinación de diferentes prestaciones y ayudas, como el apoyo en alimentación, material escolar, vivienda, ocio y limpieza. Ante casos como éstos, las entidades sociales demuestran ser el soporte que permite subsistir, ante la falta de otros apoyos, a numerosos hogares, como el de Pilar:

En Cruz Roja, me han ayudado mucho, y en Cáritas [...], me dieron el kit de higiene familiar, me dieron unas mochilas para los niños, para principio de curso, unos cuadernos, unos bolis, o sea, material escolar (Pilar, 33 años, Navarra).

Sin embargo, el apoyo de las entidades sociales en estas circunstancias tan extremas no sólo se identifica en los aspectos mencionados, sino que su dimensión más simbólica y emocional se ve reforzada por el apoyo, la orientación, el asesoramiento y la escucha que suministran. Estas menciones son especialmente explícitas en aquellas personas entrevistadas que carecen de redes sociales o que las tienen lejos, lo cual evidencia que las entidades del tercer sector son los recursos de ayuda principales para aquellos hogares con necesidades que carecen de los apoyos familiares y de amistad.

\section{Los recortes ponen en riesgo los programas de atención a las personas y reducen su capacidad técnica para intervenir}

Las realidades señaladas hasta el momento han identificado el papel fundamental que hay ejercido como soportes en esta crisis las prestaciones públicas (por desempleo -contributivas y no contributivas-, rentas mínimas y pensiones de vejez), las entidades o servicios de atención social, así como las familias o redes cercanas. Todas ellas están siendo, por un lado, el colchón que previene, amortigua y desacelera las trayectorias de exclusión, y por otro, los mecanismos que contribuyen a impulsar itinerarios de integración, como es el caso de las entidades de incorporación social. Sin embargo, los discursos analizados también alertan de que la prolongación de la crisis y los recortes en materia de protección social podría estar debilitando estos apoyos.

Los relatos ofrecen experiencias que ilustran la desigualdad de acceso a la protección social. Por un lado, las prestaciones sociales previenen y desaceleran itinerarios, pero se revelan como un recurso limitado que presenta importantes deficiencias, sobre todo, cuando las dificultades se prolongan. Asimismo, es un recurso sujeto a requisitos (de cotización, de características sociodemográficas o de temporalidad), por lo que discrimina a aquellos colectivos que, por diversas razones, han tenido tradicionalmente relaciones más precarias con el mercado de trabajo o pertenecen a núcleos familiares que, según la normativa vigente, requieren un menor nivel de protección.

Por otro lado, también se observa un progresivo aumento de discursos como el de Esmeralda, que señalan la dificultad de encontrar ayuda entre sus redes cercanas, especialmente en las familiares. Este hecho también aparece en recientes trabajos, como Moreno y Mari-Klose (2013) o Lorenzo (2014), donde se refuerzan los debates que cuestionan que las familias en España continúan teniendo la misma capacidad apoyo que venían suministrando.

Por último, los servicios sociales y las entidades de iniciativa social han demostrado ser fundamentales para apoyar a aquellos hogares sin oportunidades laborales y con importantes necesidades económicas. Sin embargo, a partir de los discursos de las personas entrevistadas y las experiencias contrastadas de más de una treintena de entidades del tercer sector en Navarra, también comienza a observarse una menor capacidad de intervención y respuesta por parte de estos programas.

\subsection{Crisis y tercer sector}

Las entidades de iniciativa social están sufriendo la crisis de manera muy intensa, que se identificaba ya en los primeros análisis económicos de estas entidades. Las razones que se señalaban eran fundamentalmente dos. En primer lugar, el constreñimiento del gasto público, que había supuesto una importante merma de su capacidad y estabilidad económica. En segundo lugar, el incremento del número de personas que atender y el elevado grado de complejidad de estas intervenciones, un elemento que ha ido progresivamente en aumento, con la prolongación de muchas situaciones de necesidad. No obstante, si bien el impacto era predecible, su intensidad ha sobrepasado previsiones, tal y como señala la propia Plataforma del Tercer Sector (2012).

Una de las razones que han contribuido a afianzar este impacto es aquella que tiene que ver con la propia configuración del sector. El diagnóstico elaborado para el I Plan Estratégico del Tercer Sector de Acción Social en España señalaba que las principales actuaciones de las entidades que lo conforman tenían como sujeto de intervención a población excluida o en riesgo de exclusión social y se consolidaban como un productor de servicios destinados a la población con mayores dificultades (Plataforma de ONG de Acción Social, 2010, 2012). 
En las últimas décadas, la diversificación de necesidades sociales ha dado lugar en Navarra a la promoción de servicios y programas de atención social con alto grado de especialización por colectivos, fundamentalmente gestionados por entidades del tercer sector. Esto ha llevado a las entidades a constituirse como empresas sociales con alto grado de profesionalización y especialización en la atención a los colectivos con necesidades sociales, por un lado, y a desarrollar una interesante articulación y colaboración con los servicios públicos, por otro. Sin embargo, también ha generado una elevada dependencia financiera de la Administración (Aguiar, 2006; Caria y Pereira, 2014).

Este análisis del caso de Navarra ha constatado que los efectos más agudos de la crisis están siendo la reducción de los equipos técnicos de las entidades del tercer sector, la limitación de las intervenciones, programas y servicios de lucha contra la exclusión social, e incluso, la fusión de entidades y programas con el fin de evitar la desaparición de muchos de estos servicios. A esta realidad económica, se le suma el incremento de las necesidades sociales de los hogares, lo cual se ha traducido en un crecimiento exponencial del número e intensidad de las dificultades de los usuarios y usuarias de estas entidades. Los efectos de este desajunte en la capacidad técnica y económica de desarrollar los servicios, junto con el mencionado aumento de la demanda, han supuesto una importante merma de la calidad e intensidad de los servicios, tal y como se detalla a continuación.

\subsubsection{El recorte transversal afecta de manera intensa al tercer sector}

Los recortes en materia de política social no han sido las únicas causas de la reducción e inestabilidad del presupuesto público. Muchos de los programas que estas entidades desarrollaban se enmarcaban en la lucha contra la exclusión social a través de programas orientados a la prevención de la exclusión sanitaria, educativa o residencial, así como a programas de incorporación social vinculados al acceso al mercado de trabajo de los colectivos con mayores dificultades, por lo que la reducción presupuestaria en educación, salud, vivienda y empleo también ha contribuido a que algunos de estos programas se hayan reducido o incluso hayan desaparecido. En el caso de Navarra, las áreas de intervención social más afectadas por los recortes han sido la laboral, la de vivienda, y la de intervención social y familiar con colectivos específicos.

\subsubsection{La atención a los usuarios es compleja en un contexto sin empleo y con menos apoyos a la incorporación}

El ámbito laboral ha sido una de las aéreas de intervención social más castigadas. Ello se debe tanto al incremento de la demanda y la prolongación de muchos itinerarios de búsqueda de empleo por la falta de oportunidades laborales, como a la pérdida de recursos para la financiación de programas de empleo protegido. Como resultado, algunas entidades especializadas en la incorporación laboral de colectivos específicos, como mujeres, personas con discapacidad, parados de larga duración o personas de etnia gitana, entre otras, han visto muy mermados sus programas, y con ello, la condena de muchos de sus usuarios al desempleo.

Curiosamente, la pérdida de financiación para los programas de empleo ha venido de la mano de la modificación de la renta de inclusión social en Navarra ${ }^{5}$, que ha implicado, por un lado, la pérdida de peso del derecho subjetivo a tener unos ingresos mínimos, y por otro, la orientación clara hacia la activación. A pesar de ello, programas de incorporación laboral muy bien valorados por los profesionales, como el de empleo social protegido ${ }^{6}$, han visto reducido su presupuesto más de la mitad entre 2011 y 2013. Al mismo tiempo, se han puesto en marcha otras fórmulas de subvención para contratar directamente a perceptores de la renta de inclusión social. Sin embargo, ninguna se asemeja al empleo social protegido en cuanto a capacidad de acompañar y formar en la búsqueda de empleo.

\subsubsection{Las dificultades se acumulan en los hogares y la falta de atención puede provocar situaciones irreversibles}

La extensión de las dificultades en las familias ha empeorado sus condiciones de vida, ha cuestionado la satisfacción de sus necesidades más básicas, y ha alterado las formas de convivencia y relación. Tal y cómo se constata en otros análisis cualitativos centrados en las condiciones de vida de los hogares (Lasheras y Martínez Virto, 2013), la crisis ha incrementado las situaciones de estrés y conflictividad familiar. Ante esta realidad, el riesgo de perder la protección familiar ha convertido al capital social en un aspecto prioritario que proteger.

Por el contrario, los programas de intervención sociofamiliar y de menores también se han visto reducidos, especialmente en las zonas rurales. Igualmente, han desaparecido muchas subvenciones destinadas a campañas de sensibilización social con colectivos tradicionalmente discriminados, así como aquéllas destinadas a promover políticas y acciones de igualdad de trato.

${ }^{5}$ La Ley Foral 1/2012 sustituyó la renta básica navarra por la renta de inclusión social. Este cambio implicó la ampliación de los requisitos de acceso y el aumento de las situaciones de exclusión a la norma por criterios, por ejemplo, de situación administrativa. La modificación ha tenido una fuerte contestación social, que ha provocado hasta tres cambios legislativos (leyes forales 36/2013, 13/2014 y 6/2015). A pesar de estas modificaciones, que han ido reduciendo las situaciones de desprotección, la prestación ha perdido capacidad protectora con respecto a su predecesora renta básica.

${ }^{6}$ Programa de incorporación laboral orientado a personas con dificultades de acceso al mercado de trabajo que combina la contratación de seis meses (en ocasiones ampliable a otros seis más) para la realización de diversas tareas, con la cualificación profesional y formación relacionada con las habilidades sociales y laborales. 
También en este ámbito se ha constatado una importante reducción en los programas que muchas entidades del tercer sector desarrollaban para prevenir el fracaso escolar, o para prevenir e intervenir en materia de drogodependencias. En estos casos, numerosos programas han tenido que reducir su atención, o desaparecer, por sufrir recortes que van del $50 \%$ al $100 \%$ de la subvención.

Entre los colectivos más afectados por estos recortes, destacan, por un lado, los menores de etnia gitana, que han visto reducida la subvención de los programas de promoción educativa y seguimiento escolar, y por otro, los jóvenes y adultos con conductas de riesgo en materia de consumo.

Las políticas de inclusión destinadas a promover el acceso a la formación y prevenir las drogodependencias en los menores y jóvenes de entornos desfavorecidos contribuían a prevenir que sus hogares se enquistaran en la exclusión social. La falta de atención que, tras los recortes de muchos programas, tienen muchas familias favorece, por el contrario, la cronificación de las situaciones de exclusión social en muchos hogares y, como ocurre en el caso de las personas de etnia gitana, también en su comunidad.

\subsubsection{Las profesionales están sobrecargadas y exhaustas}

Una de las consecuencias más señaladas de la reducción presupuestaria en las entidades de iniciativa social ha sido la forzada reducción de personal. La pérdida de subvenciones, el retraso en la concesión y publicación de los concursos públicos, la paralización de programas por la falta de acuerdo parlamentario, entre otras, han sido las razones más comunes que han contribuido a la inestabilidad económica de muchas entidades sociales. En esta línea, la falta de capacidad económica de las entidades para enfrentar estos retrasos ha tenido importantes efectos en las condiciones laborales de su equipo técnico. Esta inestabilidad ha puesto en riesgo muchos programas, ha reducido los equipos y sobrecargado a sus trabajadoras.

Ante la falta de recursos, la mayoría de las entidades han apostado, en primera instancia, por mantener los programas y continuar atendiendo a los y las usuarias. La pérdida de fondos era, por tanto, asumida por la entidad y por las personas trabajadoras, a través de bajada de salarios, reducciones de jornada e incluso despidos. Algunas entidades navarras estiman que ha habido recortes de salarios de toda la plantilla de hasta un $8,5 \%$; reducciones a jornada parcial para al menos tres cuartas partes de la plantilla de media; y, en los casos más graves, despidos de trabajadores, primero aquellos encargados de las labores administrativas y después las/os técnicas/os de intervención social.

Si bien uno de los aspectos más relatados por las entidades sociales ha sido el esfuerzo realizado por los equipos para evitar reducir la calidad de los pro- gramas y servicios ofrecidos, todas ellas concluyen que el progresivo empeoramiento de las condiciones económicas, el aumento de la demanda potencial y la prolongación de estas situaciones han hecho que, de manera paulatina, la sobrecarga de trabajo, la inestabilidad de las condiciones laborales y el cansancio de los equipos de trabajo resten calidad a los servicios.

\subsubsection{Sin recursos técnicos, la calidad de las intervenciones se reduce}

El mencionado aumento de la demanda en los servicios de atención a las personas y los recortes en políticas sociales han puesto en riesgo, como resultado de las peores condiciones técnicas, la calidad de muchos de los programas de incorporación social. Como consecuencias más directas, se señalan la reducción de personas atendidas, los procesos de incorporación social paralizados y una disminución del acompañamiento social.

A modo de ejemplo, la reducción del número de personas atendidas en algunos programas de atención y formación a jóvenes y adultos alcanza a más de 200 personas por programa y año. Del mismo modo, otras actividades de acogida y orientación, o de atención especializada, se han reducido de manera importante, por la saturación de las personas trabajadoras y la falta de recursos, lo que ha dado lugar a menor intensidad y cobertura en los procesos de intervención.

Este último aspecto es el más señalado en las entidades sociales dedicadas a la incorporación social. Con los recortes, las labores de acompañamiento, formación, intermediación y asesoramiento del autoempleo han reducido el número de intervenciones individualizadas y adaptadas a los itinerarios de empleabilidad. El resultado ha sido la imposibilidad de continuar con algunas intervenciones; la limitación temporal de los itinerarios (antes no la tenían, y ahora se desarrollan durante seis meses); la reducción del impacto de los programa en términos de eficacia, eficiencia y efectividad; un aumento de las listas de espera de hasta dos meses para iniciar un itinerario; o la pérdida de profesionales de referencia, por la inestabilidad laboral de las plantillas. Actualmente, la carga de trabajo y los menores recursos obligan a realizar la orientación laboral en grupo, reduciendo las atenciones individuales, y eliminando el seguimiento y acompañamiento social. Así mismo, la inexistencia de recursos formativos y de mejora de empleabilidad para prevenir la exclusión, y la falta de contacto con el mundo laboral que se facilitaba a través de las prácticas agravan esta situación.

En definitiva, a lo largo de este apartado se han podido comprender algunas de las dificultades con las que los/as usuarios/as y las entidades sociales del tercer sector en Navarra se enfrentan cada día. La reducción presupuestaria de muchos programas y la acumulación de problemas en muchos hogares hacen compleja la intervención y fuerzan, en ocasiones, a 
responder a lo más urgente y de manera rápida, sin tener la oportunidad de intervenir con metodologías como el acompañamiento social en itinerarios de incorporación, las cuales han demostrado ser muy eficaces en la lucha contra la exclusión social. En ocasiones, la reducción de aportaciones públicas se ha visto amortiguada por un incremento de las donaciones particulares y del número de personas voluntarias que colaboran con estas instituciones ${ }^{7}$ (Homs i Ferret, 2009; Cáritas, 2013). Sin embargo, a pesar de la encomiable labor del voluntariado, la profesionalización de estas entidades está en riesgo.

\section{Reflexiones y retos en un contexto de austeridad}

El aumento de las dificultades en el acceso al mercado de trabajo, la falta prolongada de ingresos, el agotamiento de las prestaciones, la alta demanda de acceso a los servicios sociales o la extenuación de las familias se acumulan en muchos hogares, y dan lugar a situaciones de gran complejidad. Como se ha observado, para prevenir y amortiguar las situaciones de exclusión es importante contar con apoyos públicos, económicos y sociales que frenen las caídas. Sin embargo, la prolongación de la crisis y los recortes podrían estar poniendo en riesgo algunos de estos soportes, debido, entre otras razones, a la modificación normativa de acceso a algunas prestaciones mínimas, la reducción de las partidas presupuestarias destinadas a algunos programas de inclusión social o la sobrecarga familiar. Por tanto, la extensión de las dificultades en un escenario con menor capacidad de encontrar apoyo no ha hecho sino incrementar el riesgo de desarrollar trayectorias de exclusión más rápidas e intensas, y enquistar a muchos hogares en situaciones de exclusión severa prolongada.

Estudios en el ámbito europeo y estatal alertan sobre el riesgo que entrañan las estrategias de austeridad para las condiciones de vida de la población, y especialmente, sobre sus negativos efectos en las capas más bajas de la estructura social, lo cual intensifica la fractura social originada en los mercados laborales. Precisamente, recientes recomendaciones europeas (Frazer y Marlier, 2014) en la lucha contra la exclusión se centran en reforzar esta última red de protección, ampliando la cobertura de las rentas mínimas, incrementando la oferta de dispositivos de activación laboral para personas en riesgo de exclusión social, y fortaleciendo los programas de los servicios sociales que prestan atención en el ámbito de la familia y la inclusión social.

7 La última memoria anual de Cáritas (2013) destaca un aumento del $30 \%$ en el número de voluntarios en los últimos cinco años. En cuanto a las aportaciones de fondos públicos, las públicas se han reducido en ese mismo periodo, mientras que las privadas se han incrementado en casi un $35 \%$. Sin embargo, este incremento de donaciones no es una realidad generalizada en el tercer sector.
En este sentido, el análisis ha constatado que muchas personas y hogares no acceden a una protección económica suficiente, han visto frenados sus procesos de incorporación por la falta de recursos, limitadas sus atenciones técnicas por la incapacidad de los servicios de intervenir a través de itinerarios individualizados, o se han visto excluidas de otros servicios por las largas listas de espera. Por otro lado, la menor capacidad económica y técnica de servicios, entidades y profesionales también se ha traducido en peores condiciones de trabajo (jornadas, salarios y cargas) para las profesionales del tercer sector que atienden a estas personas.

En este escenario, las entidades del tercer sector se enfrentan al importante reto de continuar siendo referentes en la intervención especializada con algunos colectivos excluidos. Ante inestabilidad de sus ingresos, la reducción de las subvenciones, y el aumento cualitativo y cuantitativo de su demanda es necesario iniciar un espacio de reflexión sobre:

- Cómo atender a una demanda creciente, con más necesidades y con dificultades más intensas.

- Cómo cuidar de los equipos humanos, actualmente exhaustos por la falta de estabilidad laboral, el aumento del trabajo y el progresivo empeoramiento de sus condiciones laborales.

- Cómo garantizar mecanismos de financiación que no dependan de los vaivenes políticos y que, sin renunciar a defender la responsabilidad pública de atender a la población más vulnerable con programas especializados, eviten paralizar servicios y programas ante la falta de acuerdo presupuestario en el pago de muchas subvenciones o servicios prestados.

La huella de la crisis puede resultar irreversible en muchos hogares, pero puede también acabar con la profesionalización de algunas entidades del tercer sector. Por ello, es fundamental que las estrategias de sostenibilidad de estos programas continúen apostando por la calidad en sus intervenciones:

- Promoviendo itinerarios de incorporación laboral adaptados que lleven a una inclusión laboral estable. Para ello, es fundamental la intermediación con empresas y sectores productivos, el acompañamiento social y la demanda de políticas de activación adaptadas a los colectivos con dificultades severas de acceso al mercado de trabajo.

- Abogando por la intervención adaptada a las especificidades de las personas, defendiendo las altas dosis de acompañamiento social que requieren sus usuarios/as, y manteniendo los sistemas de evaluación y revisión de sus actuaciones. La falta de tiempo, medios económicos y equipos humanos puede llevar al error de no reflexionar sobre las formas de trabajo. La evaluación a partir de los resultados y la reflexión sobre la metodología de intervención es imprescindible para avanzar en la consolidación del trabajo social como profesión. 
Los resultados y reflexiones que se han presentado se deben a la experiencia de 52 usuarios/as y de una treintena de entidades del tercer sector en Navarra, por lo que no son generalizables al resto y deben ser cuidadosamente interpretados en una posible comparación estatal. Sin embargo, resultan de interés como muestra de los riesgos y dificultades a los que se enfrenta el sector en términos de profesionali- zación de sus equipos y de calidad de sus intervenciones. Por tanto, de manera indirecta, la realidad descrita podría tener importantes costes en términos de cohesión social, debido a que el análisis evidencia que las entidades del tercer sector son recursos fundamentales que forman parte de la última red de protección social de las familias en situación de exclusión.

\section{Bibliografía referenciada}

AGUIAR, F. X. (2006): “Tercer sector: análisis, desafíos y competencias desde el trabajo social", Acciones e Investigaciones Sociales, $\mathrm{n}$ - extra 1, págs. 439 ss.

CANTÓ, O. (2010): "El impacto de la crisis económica sobre los hogares más desfavorecidos”, Revista Española del Tercer Sector, nำ15 [khttp://www. luisvivesces.org/rets/15/>].

CARIA, T.; y PEREIRA, F. (coords.) (2014): Trabalho Social Profissional no Terceiro Setor, Viseu, Psicosoma.

CÁRITAS (2013): Memoria 2013, Madrid, Cáritas [‘http:// www.caritas.es/memoria2013/>].

FRAZER, H.; y MARLIER, E. (2014) Investing in Children: Breaking the Cycle of Disadvantage: A Study of National Policies, Luxemburgo, Oficina de Publicaciones de la Unión Europea [<http:// ec.europa.eu $/$ social $/$ main.jsp?catld=738\&langl $\mathrm{d}=$ en\&publd $=7708 \mathrm{~s}$.

HOMS I FERRET, O. (coord.) (2009): Los retos del Tercer Sector ante la crisis, serie Cuadernos de Debate, no 6, Madrid, Fundación Luis Vives [rhttp://www.luisvivesces.org/upload/78/91/ Cuaderno_VI_bja2.pdf)].

INSTITUTO NACIONAL DE ESTADÍSTICA (2014): Encuesta de Condiciones de Vida [<http://www.ine.es/ dyngs/INEbase/es/operacion.htm?c=Estadisti ca_C\&cid=1254736176807\&menu=ultiDatos\& $i$ $\mathrm{dp}=1254735976608>]$.

LAPARRA, M. (coord.) (2015): La desigualdad y la exclusión que se nos queda. II Informe CIPARAIIS sobre el impacto social de la crisis, Barcelona, Edicions Bellaterra.

LAPARRA, M.; y PÉREZ ERANSUS, B. (coords.) (2011): El primer impacto de la crisis en la cohesión social, Madrid, Fundación FOESSA; Cáritas Española Editores.

LASHERAS, R.; y MARTÍNEZ VIRTO, L. (2013): “Crisis concatenadas", Inguruak, n- 53-54, págs. 682-693.

LORENZO, F. (2014): VII Informe sobre exclusión y desarrollo social en España, Madrid, Fundación FOESSA; Cáritas Española Editores [<http://www. foessa2014.es/informe/>].
MARTÍNEZ VIRTO, L. (2013): “Una aproximación a los procesos de exclusión surgidos en Navarra tras el impacto de la crisis: la solidaridad informal como amortiguadora de las dificultades", en HERNÁNDEZ-ARISTU, J., Trabajo Social, una perspectiva europea, Pamplona, Eunate.

MORENO, L.; y MARI-KLOSE, P. (2013): "Youth, family change and welfare arrangements: Is the South still so different?", European Societies, vol. 15, nํㅜ 4, págs. 493-513.

NAVARRA (2015): “Ley Foral 6/2015, de 5 de marzo, de Modificación de la Ley Foral 1/2012, de 23 de enero, por la que se regula la Renta de Inclusión Social", Boletín Oficial de Navarra, no 51, 16-3-15 [khttp://www.lexnavarra.navarra. es/detalle.asp? $r=35490$ >].

- (2014): “Ley Foral 13/2014, de 18 de junio, de modificación de la Ley Foral 1/2012, de 23 de enero, por la que se regula la Renta de Inclusión Social", Boletín Oficial de Navarra, no 129, 3-7-14 [<http://www.lexnavarra.navarra. es/detalle.asp? $r=34108>$ ].

- (2013): “Ley Foral 36/2013, de 26 de noviembre, de modificación de la Ley Foral 1/2012, de 23 de enero, por la que se regula la Renta de Inclusión Social", Boletín Oficial de Navarra, no 233, 4-12-13 [<https://www.navarra.es/ home_es/Actualidad/BON/Boletines/2013/233/ Anuncio-3/>].

- (2012): “Ley Foral 1/2012, de 23 de enero, por la que se regula la Renta de Inclusión Social”, Boletín Oficial de Navarra, no- 24, 3-2-12 [<http://www. lexnavarra.navarra.es/detalle.asp? $r=25537$ 〉].

PLATAFORMA DE ONG DE ACCIÓN SOCIAL (2012): Diagnóstico del Tercer Sector de Acción Social, Madrid, Ministerio de Sanidad, Servicios Sociales e Igualdad.

- (2010): Propuestas para mejorar la financiación pública del Tercer Sector de Acción Social, Madrid, Plataforma de ONG de Acción Social.

PLATAFORMA DEL TERCER SECTOR (2012): Propuestas de la Plataforma del Tercer Sector para afrontar el impacto social de la crisis [rhttp://www. plataformatercersector.es/sites/default/files/ Documento $\% 20$ Propuestas $\% 20$ Crisis $\% 20$ FINAL.doc)]. 